\title{
Updated guidelines on the preoperative staging of thyroid cancer
}

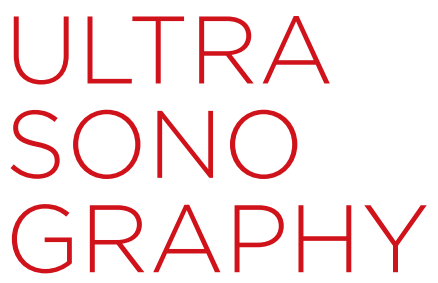

Hye Jung Kim

Department of Radiology, Kyungpook National University Medical Center, Daegu, Korea

Recent studies have provided prognostic information and recommendations for staging thyroid cancers that have changed the staging and management guidelines for the disease. Consequently, minimal extrathyroidal extension (ETE) was removed from the T3 stage classification in the eighth edition of the TNM staging system by the American Joint Committee on Cancer. New T categories have been subsequently added, including T3a, defined as a tumor $>4 \mathrm{~cm}$ in its greatest dimension, limited to the thyroid gland, and T3b, defined as a tumor of any size with gross ETE invading only the strap muscles. In this article, the author reviews the changes in the TNM staging system for thyroid cancer, with an emphasis on ultrasonography in preoperative staging.

Keywords: Thyroid neoplasms; Neoplasm staging; Ultrasonography

\section{Introduction}

The incidence of thyroid cancer has increased worldwide over the past few decades [1]. Papillary thyroid cancer (PTC) is the most common type of thyroid cancer, but is the least aggressive histologic subtype, with a 10-year survival rate exceeding 95\% [1-4]. In South Korea, the incidence of thyroid cancer has rapidly increased, and thyroid cancer is now the most common type of cancer in the country $[3,4]$. This change in incidence is the result of a major increase in the diagnoses of relatively small $(<1 \mathrm{~cm})$ PTCs, with a much smaller increase in the diagnoses of larger tumors [5]. Despite this shift, roughly two-thirds of patients still undergo total thyroidectomy and one-third undergo lobectomy $[6,7]$. If the primary thyroid carcinoma is a small, unifocal, intrathyroidal carcinoma without regional or distant metastasis, lobectomy is strongly recommended [8]. Therefore, it is crucial to determine the appropriate extent of surgery and management in patients with thyroid malignancies by using precise preoperative ultrasonography (US) to evaluate the primary tumor, multifocality, bilaterality, and central and lateral lymph node (LN) metastasis. Recently, the eighth edition of the AJCC Cancer Staging Manual was released (Tables 1, 2) [9]. Several major changes have been made in the staging of thyroid cancer, with new and validated evidence supporting a more personalized approach (Table 3).

In this article, the author reviews the radiologic and clinical aspects of the changes in the TNM staging system for thyroid cancer in the eighth edition of the AJCC Cancer Staging Manual.

This is an Open Access article distributed under the terms of the Creative Commons Attribution NonCommercial License (http://creativecommons.org/ licenses/by-nc/3.0/) which permits unrestricted noncommercial use, distribution, and reproduction in any medium, provided the original work is properly cited.

Copyright (C) 2017 Korean Society of Ultrasound in Medicine (KSUM)

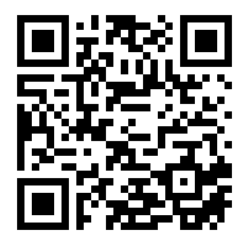

How to cite this article:

Kim HJ. Updated guidelines on the preoperative staging of thyroid cancer. Ultrasonography. 2017 0ct;36(4):292-299. 


\section{Issue 1: T Staging}

T staging is based on tumor size and the degree of locoregional invasion. The previously established US criteria for extrathyroidal extension (ETE), including minimal ETE, consist of contact with the adjacent thyroid capsule along more than $25 \%$ of the perimeter of the tumor, loss of echogenic line, and a tumor mass bulging from normal thyroid tissue (Fig. 1) [10,11]. Two different studies have reported the sensitivity, specificity, positive predictive value, negative predictive value, and accuracy for ETE on US to be $86.2 \%$ and $74.3 \%, 55.3 \%$ and $66.1 \%, 70.9 \%$ and $56.5 \%, 76.0 \%$ and $81.3 \%$, and $72.6 \%$ and $69.1 \%$, respectively $[11,12]$. In addition to grayscale US, some studies have suggested that elastography may help predict ETE. They have shown that a hard malignancy, as indicated by the Rago score in elastography or the quantitative elasticity index (EI) in shear wave elastography (SWE), may be an independent or complimentary factor in predicting pathologic ETE [13-15]. Furthermore, Gweon et al. [16] have reported that adding 3-dimensional (3D) US to 2-dimensional (2D) US could improve diagnostic accuracy (60.8\% for 2D US vs. $67.9 \%$ for the combination of 2D US and 3D US) and interobserver agreement for predicting the ETE of papillary thyroid carcinoma. This may be because 3D US can better assess the relationship between thyroid cancer and the capsule in multiplanar sectional images, providing a more accurate evaluation of the anatomic relationship than 2D US.

ETE ranges from gross ETE, involving major structures, to minimal

Table 1. Definitions of the T categories for papillary, follicular, poorly differentiated, Hürthle cell, and anaplastic thyroid carcinoma in the eighth edition of the AJCC Cancer Staging Manual

\begin{tabular}{ll}
\hline T category & \\
\hline TX & Primary tumor cannot be assessed \\
T0 & No evidence of primary tumor \\
T1 & Tumor $\leq 2 \mathrm{~cm}$ in greatest dimension, limited to the thyroid \\
T1a & Tumor $\leq 1 \mathrm{~cm}$ in greatest dimension, limited to the thyroid \\
T1b & Tumor $>1 \mathrm{~cm}$ but $\leq 2 \mathrm{~cm}$ in greatest dimension, limited to the thyroid \\
T2 & Tumor $>2 \mathrm{~cm}$ but $\leq 4 \mathrm{~cm}$ in greatest dimension, limited to the thyroid \\
T3 & Tumor $>4 \mathrm{~cm}$ limited to the thyroid, or gross extrathyroidal extension invading only strap muscles \\
T3a & Tumor $>4 \mathrm{~cm}$ limited to the thyroid \\
T3b & of any size \\
T4 & Includes gross extrathyroidal extension \\
T4a & Gross extrathyroidal extension invading subcutaneous soft tissue, larynx, trachea, esophagus, or recurrent laryngeal nerve from a tumor \\
& of any size
\end{tabular}

Note: All categories may be subdivided: (s) solitary tumor and $(\mathrm{m})$ multifocal tumor (the largest tumor determines the classification).

Used with the permission of the American Joint Committee on Cancer (AJCC), Chicago, Illinois. The original source for this material is the AJCC Cancer Staging Manual, Eighth Edition (2017) published by Springer Science and Business Media LLC, www.springer.com [9].

Table 2. Definition of the $\mathrm{N}$ categories for thyroid carcinoma in the eighth edition of the AJCC Cancer Staging Manual

\begin{tabular}{ll}
\hline N category & \\
\hline NX & Regional lymph nodes cannot be assessed \\
N0 & No evidence of locoregional lymph node metastasis \\
N0a & One or more cytologically or histologically confirmed benign lymph nodes \\
N0b & No radiologic or clinical evidence of locoregional lymph node metastasis \\
N1 & Metastasis to regional nodes \\
N1a & Metastasis to level VI or VII (pretracheal, paratracheal, or prelaryngeal/Delphian, or upper mediastinal) lymph nodes. This can be unilateral \\
N1b & or bilateral disease. \\
\hline
\end{tabular}

Used with the permission of the American Joint Committee on Cancer (AJCC), Chicago, Illinois. The original source for this material is the AJCC Cancer Staging Manual, Eighth Edition (2017) published by Springer Science and Business Media LLC, www.springer.com [9]. 
ETE. Historically, if PTC was found with minimal ETE (microscopic tumor extension to the sternothyroid muscle or perithyroidal soft tissue), it was upgraded to T3. However, the thyroid often has an incomplete fibrous capsule, making it occasionally problematic to determine whether the boundary between the thyroid cancer and fibroadipose tissue indicates an invasive process or simply the absence of a thyroid capsule. Consequently, it is difficult for radiologists to evaluate the continuity of the thyroid capsule on US. Furthermore, the thyroid gland may contain adipose tissue and skeletal muscles, and these structures, in association with thyroid carcinoma, should not be used as indicators of ETE [17].

Several recent studies have demonstrated that minimal ETE is less significant than gross ETE in terms of survival and recurrence. In these studies, the risk of recurrence associated with minimal ETE was found to range from $3 \%$ to $9 \%$, while the risk of recurrence in patients with gross ETE was found to range from 23\% to $40 \%$ $[8,18-21]$. In differentiated thyroid cancer, gross ETE has been found to decrease survival, but no studies have demonstrated that minimal ETE is an independent predictor of recurrence or survival $[9,19,22,23]$. Consequently, minimal ETE has been removed from the definition of T3 disease in the eighth edition of the TNM staging system by American Joint Committee on Cancer (AJCC), and as a result, minimal ETE no longer affects the T category. Furthermore, T3b is now defined as a tumor of any size with gross ETE invading only the strap muscles (the sternohyoid, sternothyroid, thyrohyoid, or omohyoid muscles), and T3a refers to a tumor $>4 \mathrm{~cm}$ in its greatest dimension, limited to the thyroid gland. It should, however, be noted that the aforementioned studies for predicting ETE on US included both minimal and gross ETE. In a recent study, US criteria for minimal and gross ETE were suggested. The study reported that bulging from a discontinuous thyroid capsule and bulging from an invisible thyroid capsule on US were significantly associated with gross ETE, while a tumor mass abutting an invisible thyroid capsule on US was associated with minimal ETE (Figs. 2, 3) [24]. Further

Table 3. Summary of changes regarding differentiated and anaplastic thyroid carcinomas in the eighth edition of the AJCC Cancer Staging Manual

\begin{tabular}{|c|c|}
\hline Change & Details of change \\
\hline $\begin{array}{l}\text { Prognostic factors required for } \\
\text { stage grouping }\end{array}$ & The age at diagnosis cutoff used for staging was increased from 45 years to 55 years. \\
\hline Definition of primary tumor & $\begin{array}{l}\text { Minor extrathyroidal extension was removed from the definition of T3 disease. As a result, minor extrathyroidal } \\
\text { extension does not affect either T category or overall stage. }\end{array}$ \\
\hline Definition of primary tumor & T3a is a new category and refers to a tumor $>4 \mathrm{~cm}$ in greatest dimension limited to the thyroid gland. \\
\hline Definition of primary tumor & $\begin{array}{l}\text { T3b is a new category and is defined as a tumor of any size with gross extrathyroidal extension invading only strap } \\
\text { muscles (sternohyoid, sternothyroid, thyrohyoid, or omohyoid muscles). }\end{array}$ \\
\hline Definition of regional lymph nodes & $\begin{array}{l}\text { The definition of central neck (N1a) was expanded to include both level VI and level VII (upper mediastinal) lymph } \\
\text { node compartments. } \\
\text { Previously, level VII lymph nodes were classified as lateral neck lymph nodes (N1b). }\end{array}$ \\
\hline Definition of primary tumor & $\begin{array}{l}\text { Unlike previous editions where all anaplastic tumors were classified as having T4 disease, the T category for } \\
\text { anaplastic thyroid cancers will now use the same definitions used for differentiated thyroid cancers. }\end{array}$ \\
\hline
\end{tabular}

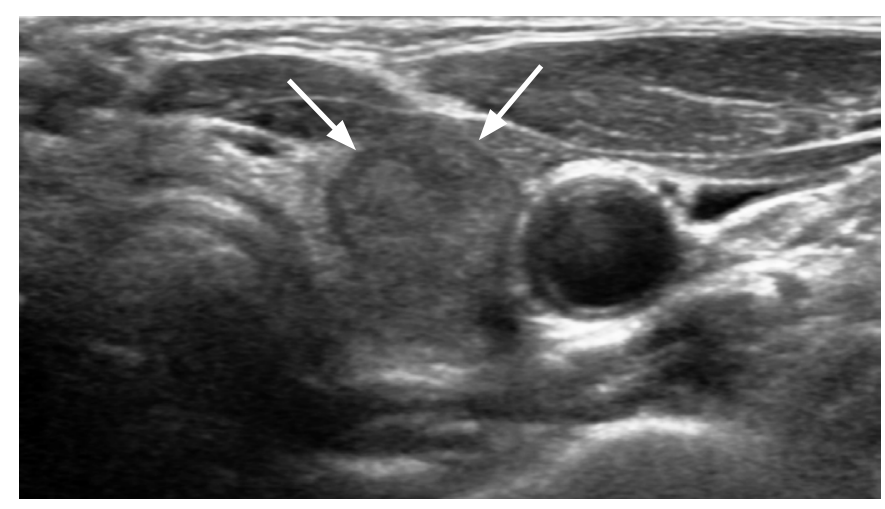

A

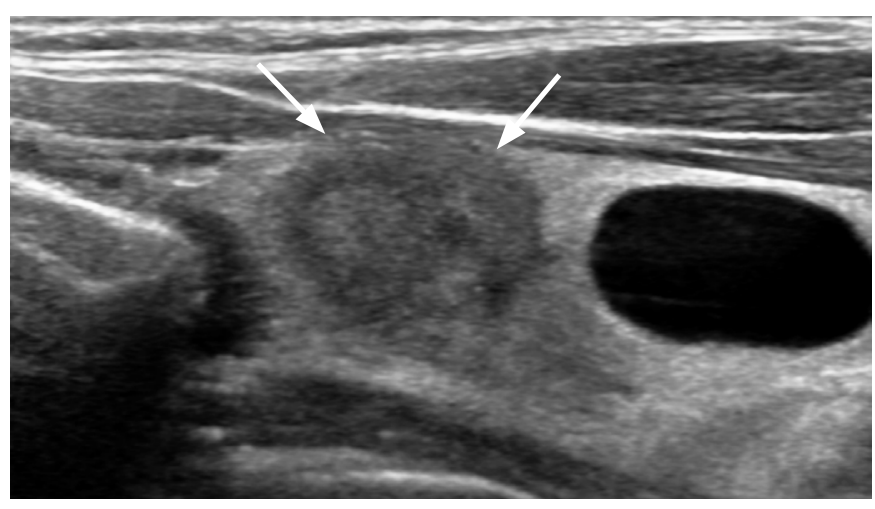

B

Fig. 1. A 70-year-old woman with minimal extrathyroidal extension.

Transverse (A) and longitudinal (B) ultrasonography reveals a 1.5-cm solid mass in the left lobe, abutting the thyroid capsule with an invisible thyroid capsule (arrows) overlying the mass. The pathologic $\mathrm{T}$ category is $\mathrm{T} 1 \mathrm{~b}$. 
large-scale research is needed to evaluate the clinical implications of these US criteria.

Other than tumors invading only the strap muscles, other types of gross ETE are classified as T4 (i.e., the same as in the seventh edition of the AJCC TNM classification) (Fig. 3). In previous American Thyroid Association (ATA) guidelines, the routine preoperative use of non-US imaging (magnetic resonance imaging [MRI], computed tomography $[\mathrm{CT}]$, and positron emission tomography) was not recommended; however, the preoperative use of neck CT (with contrast) or MRI is now recommended for patients with clinical suspicion of advanced disease to improve directed surgical therapy [8].

Although 1-year survival rates of anaplastic thyroid cancer have been found to be less than $10 \%-20 \%$, incidentally detected small anaplastic thyroid cancers that are completely resected may have a much better prognosis $[25,26]$. Therefore, the $T$ category for anaplastic thyroid cancers that were previously staged as T4 disease uses the same definitions as those used for differentiated thyroid cancers.

\section{Issue 2: N Staging}

Previously, level VII LNs were classified as lateral neck LNs (N1b). However, according to the Consensus Statement on the Terminology and Classification of Central Neck Dissection for Thyroid Cancer, the inferior border of the central compartment is defined as the innominate artery on the right and the corresponding axial plane on the left [27]. Since the thyroid gland is located near the thoracic inlet, the lymphatic drainage is contiguous with the anterior

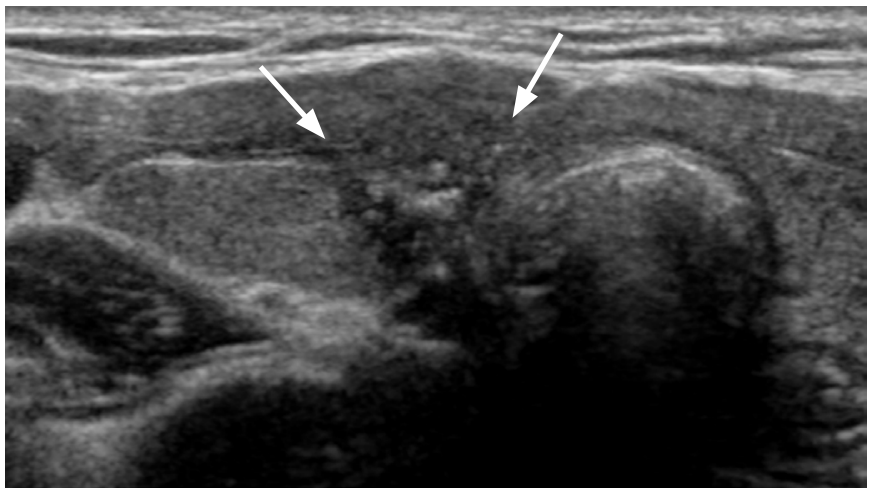

A

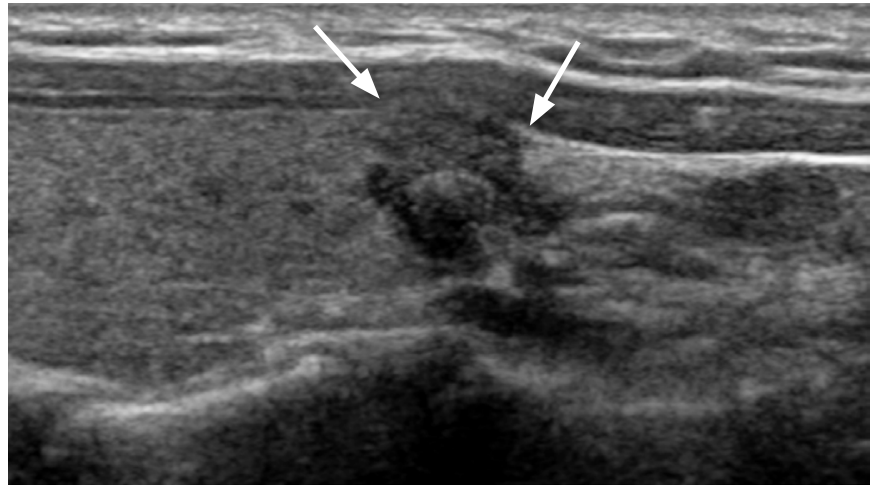

B

Fig. 2. A 39-year-old woman with gross extrathyroidal extension.

Transverse (A) and longitudinal (B) ultrasonography demonstrates a 1.0-cm solid mass in the right lobe, bulging from the normal thyroid contour with an invisible thyroid capsule (arrows) overlying the mass. The pathologic T category is T3b.

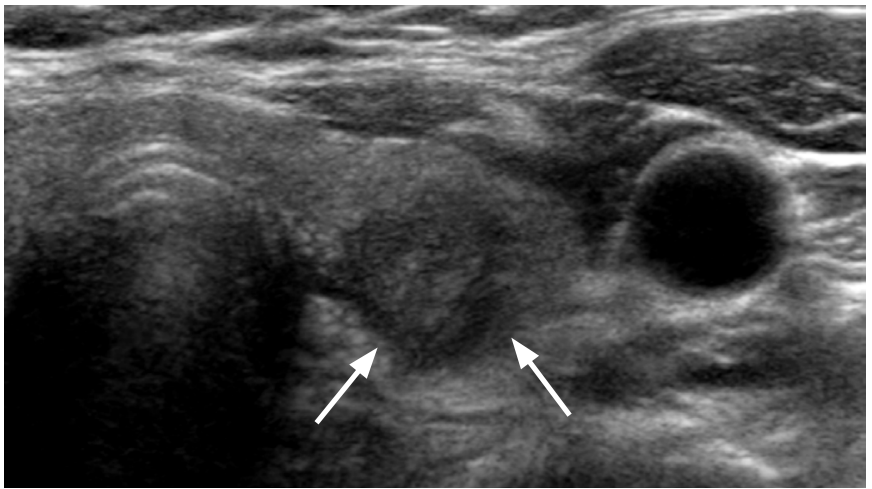

A

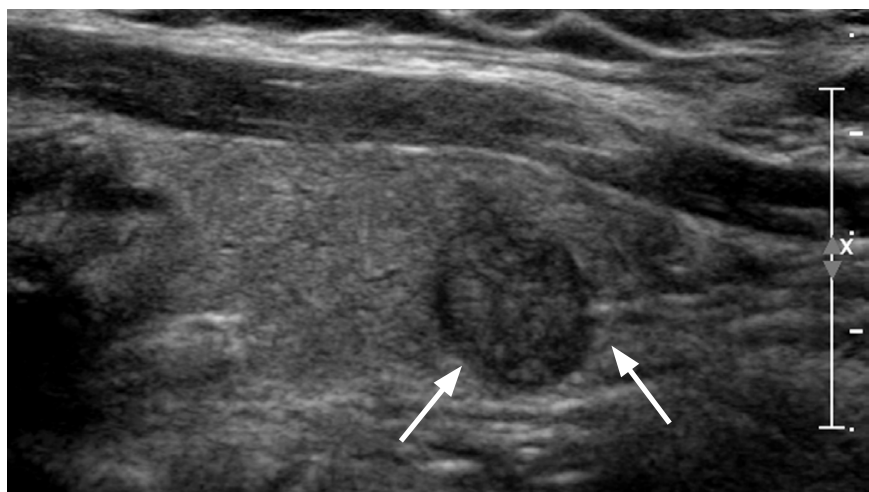

B

Fig. 3. A 55-year-old woman with gross invasion of the recurrent laryngeal nerve.

Transverse (A) and longitudinal (B) ultrasonography shows a 1.0-cm solid mass in the left lobe, bulging from the normal thyroid contour with an invisible thyroid capsule (arrows) overlying the mass. Even though ultrasonography cannot directly assess recurrent laryngeal nerve invasion, this can be expected considering the tumor location. Recurrent laryngeal nerve invasion was confirmed pathologically. Therefore, the pathologic T category is T4a. 


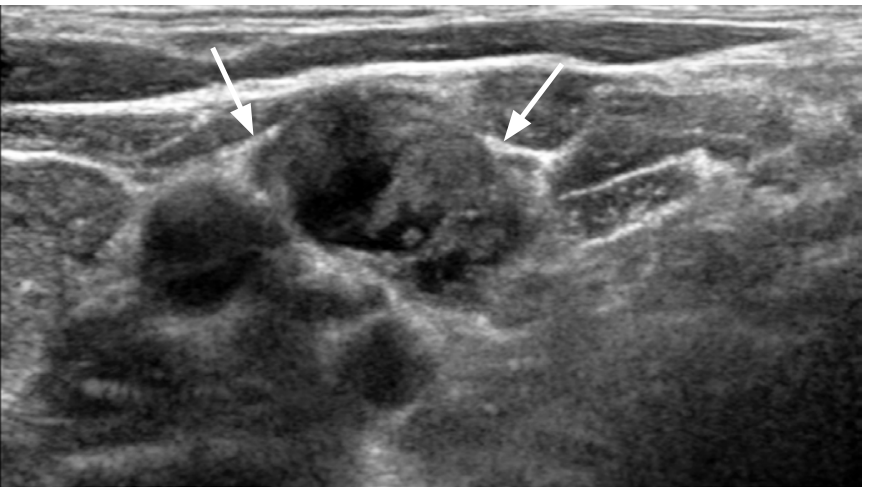

A

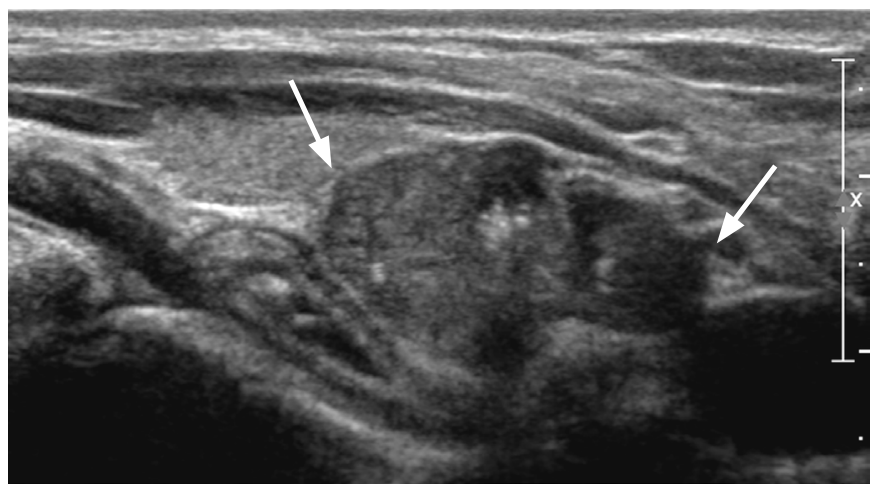

B

Fig. 4. A 32-year-old woman with metastatic lymph nodes on the left side of the neck.

Transverse (A) and longitudinal (B) ultrasonography shows the loss of fatty hilum, microcalcifications, hyperechogenicity, and cystic changes (arrows) in the lymph node.

superior mediastinum, which is accessible via a cervical approach. Therefore, the definition of the central neck compartment (N1a) was expanded to include both level VI and level VII (upper mediastinal) LN compartments in the eighth edition of the AJCC Cancer Staging Manual [9].

US features that are known to suggest a malignant $L N$ are loss of fatty hilum, a round shape, the presence of calcification, the presence of cystic changes, hyperechogenicity, and peripheral or chaotic vascularity (Fig. 4) [28-30]. However, some researchers have reported that the loss of fatty hilum, with its high sensitivity and low specificity, should not be used to indicate metastatic cervical LNs. US criteria excluding the loss of fatty hilum were found to have a higher accuracy than criteria that included the loss of fatty hilum (89\% vs. $86 \%$, respectively). Similarly, US criteria excluding the loss of fatty hilum also had a significantly higher area under the curve value than the criteria that included the loss of fatty hilum ( 0.830 vs. 0.704 , respectively) [28].

In clinical practice, non-specific cervical lymphadenopathy is commonly found on routine US imaging and cannot be confidently classified as cN0 or CN1. Therefore, US-guided fine-needle aspiration (FNA) of suspicious LNs $\geq 8 \mathrm{~mm}$ in their smallest dimension may be recommended if the results of the biopsy would change the initial management of the patient [8]. However, based on the revised consensus statement and recommendations for US diagnosis and imaging-based management of thyroid nodules by the Korean Society of Thyroid Radiology, an inadequate preoperative evaluation of cervical LNs would eventually result in recurrent or persistent disease in the neck. Hence, FNA is recommended for suspicious LNs with a short diameter of $>3-5 \mathrm{~mm}$ and indeterminate LNs (LNs showing the loss of both central hilar fat and central hilar vascularity on US) with a short diameter of $>5 \mathrm{~mm}$ in patients with thyroid cancer [31]. Furthermore, the detection of thyroglobulin in the washout fluid from FNA can suggest LN metastasis with excellent sensitivity and specificity, particularly in cystic metastatic LNs that tend to show a higher incidence of false negative results on cytology than metastatic LNs without cystic changes $[30,32,33]$.

Much research has demonstrated that US has a low sensitivity $(9.5 \%-61 \%)$ for central compartment metastasis and a high sensitivity $(64 \%-93.9 \%)$ for lateral compartment metastasis in the preoperative detection of LN metastasis from PTC $[11,12,30,34]$. The low sensitivity of US for detecting central compartment metastasis may be due to the small size of metastatic LNs or limitations in accessing this region due to surrounding structures, such as the overlying thyroid gland, clavicle, sternum, and tracheal air shadow [35]. However, the clinical implication of micrometastases is likely less significant than that of macrometastases. The direct effect of the prophylactic removal of clinically not evident level VI LNs on longterm outcomes is small, and microscopic nodal positivity does not have the same risk of recurrence as macroscopic clinically detectable disease [36-38]. A recent study reported that preoperative central neck US detects only macroscopic surgical disease, and negative findings on US can predict excellent long-term regional control and survival in patients with PTC [39]. According to the ATA guidelines, prophylactic central neck dissection is not recommended for patients with small (T1 or T2) PTC and clinically negative LNs [8]. Therefore, US can be used to detect clinically relevant nodal disease, and conservative management of the central neck compartment in the absence of abnormal findings on US should be considered.

US elastography can be used as a complementary tool in assessing cervical LNs [40]. In general, metastatic LNs demonstrate greater stiffness than benign LNs. Hence, a score of 1-2 on the elastography scale suggests a benign $L N$, and a score of 3-4 implies 
a malignant LN. Furthermore, SWE EI values are significantly higher in metastatic LNs than in benign LNs [41,42]. According to the existing research, the SWE El could be used as a predictive factor for pathologic extranodal extension, preoperatively.

Lee et al. [43] reported that tissue anisotropy and static stretch stress affected elasticity measurements. In their study, the mean El values of the cervical LNs were statistically higher when the US probe was placed parallel to the fibers of the sternocleidomastoid muscle. Furthermore, stretch stress affected the mean El values only when the US probe was parallel to the fiber orientation. Therefore, the direction of US scanning in cervical LNs should be considered when SWE El values are measured.

\section{Issue 3: Clinical Factors Affecting Preoperative US Staging}

The known US features of diffuse thyroid disease (DTD) include decreased or increased parenchymal echogenicity, a heterogeneous echotexture, micronodularity, and scattered microcalcifications $[44,45]$. Heterogeneous echogenicity and micronodularity of DTD found during US may influence the diagnostic performance of preoperative US staging, especially with respect to the detection of multifocality. However, Herh et al. [46] reported that heterogeneous echogenicity of the thyroid parenchyma did not significantly affect the ability to detect multifocality in PTC during preoperative US staging. Nevertheless, the sensitivity of preoperative US in the prediction of unilateral and bilateral multifocality among patients with PTC has been found to be relatively low, ranging from $48.6 \%$ to $67.1 \%[7,46,47]$. Thus, the risk of multifocality cannot be completely ruled out.

DTD can also affect the accuracy in predicting LN metastasis $[7,48]$. One study found that cervical lymphadenopathy that was related to the underlying DTD was a cause for incorrect N staging [49]. Choi et al. [7] found that US accuracy for NO staging was significantly lower in patients with DTD (48.8\%) than in patients without DTD (70.2\%); however, accuracies for $\mathrm{N} 1$ were not found to be significantly different. As the type of therapeutic LN dissection is determined by lateral neck node metastasis during preoperative examination, the high sensitivity of US for lateral LN metastasis, as previously reported, may contribute to proper surgical treatment. However, careful US assessment and US-guided aspiration of suspicious LNs may be helpful for the evaluation of $\mathrm{N}$ staging when a patient with PTC is suspected to have underlying DTD during preoperative US.

Recent reports have shown that in patients with PTC, a high body mass index (BMI) was strongly associated with a more advanced TNM stage and more aggressive pathologic features at presentation $[50,51]$. Furthermore, Choi et al. [52] reported that preoperative
US staging demonstrated a significantly lower negative predictive value and accuracy in detecting central LN metastasis in obese patients $\left(\mathrm{BMI} \geq 30 \mathrm{~kg} / \mathrm{m}^{2}\right.$ ) than in non-obese patients (BMI $<30$ $\left.\mathrm{kg} / \mathrm{m}^{2}\right)(53.1 \%$ vs. $71.7 \%)$. This may be attributed to the limited applicability of US in the central neck compartment as a result of the thick subcutaneous fat in the obese patients.

Recently, the cutoff in the age of diagnosis used for staging was increased from 45 years to 55 years. Several international multicenter studies have demonstrated that by changing the age cutoff from 45 years to 55 years, $10 \%$ of patients with advanced stage disease (stage III/IV) based on the original cutoff moved to stage I/ II, without impacting the survival curves in lower risk categories. In addition, the survival rates using the 55 -year-old cutoff ranged from $99.6 \%$ in stage I to $70 \%$ in stage IV, compared to the survival rates using the 45 -year-old cutoff that ranged from $99.6 \%$ in stage I to $79 \%$ in stage IV $[53,54]$. Although it seems unlikely that raising the age may critically alter the performance of the staging system, it has the clinical impact of preventing upstaging based solely on the age of diagnosis in patients between 45 years and 55 years of age who would otherwise be considered low-risk.

\section{Conclusion}

Preoperative US for evaluation of the primary tumor and LN metastasis is important for determining the extent of surgery and the proper management of patients with thyroid cancer. This study reviewed several significant changes within the AJCC staging system, as well as a variety of studies with useful information regarding preoperative US staging. Familiarity with these changes and recent knowledge of preoperative US staging will allow radiologists to share valuable information with other clinicians, thereby ensuring appropriate patient care and outcomes.

ORCID: Hye Jung Kim: http://orcid.org/0000-0002-0263-0941

\section{Conflict of Interest}

No potential conflict of interest relevant to this article was reported.

\section{References}

1. American Cancer Society. Cancer facts and figures 2016. Atlanta, GA: American Cancer Society, 2016.

2. Hundahl SA, Fleming ID, Fremgen AM, Menck HR. A National Cancer Data Base report on 53,856 cases of thyroid carcinoma treated in the U.S., 1985-1995 [see commetns]. Cancer 1998;83: 2638-2648. 
3. Oh CM, Won YJ, Jung KW, Kong HJ, Cho H, Lee JK, et al. Cancer statistics in Korea: incidence, mortality, survival, and prevalence in 2013. Cancer Res Treat 2016;48:436-450.

4. Korean Central Cancer Registry, Ministry of Health and Welfare. Annual report of cancer statistics in Korea in 2014. Sejong: Ministry of Health and Welfare, 2016.

5. Cho BY, Choi HS, Park YJ, Lim JA, Ahn HY, Lee EK, et al. Changes in the clinicopathological characteristics and outcomes of thyroid cancer in Korea over the past four decades. Thyroid 2013;23:797804.

6. Ahn HS, Kim HJ, Welch HG. Korea's thyroid-cancer "epidemic": screening and overdiagnosis. N Engl J Med 2014;371:1765-1767.

7. Choi JS, Chung WY, Kwak JY, Moon HJ, Kim MJ, Kim EK. Staging of papillary thyroid carcinoma with ultrasonography: performance in a large series. Ann Surg Oncol 2011;18:3572-3578.

8. Haugen BR, Alexander EK, Bible KC, Doherty GM, Mandel SJ, Nikiforov YE, et al. 2015 American Thyroid Association management guidelines for adult patients with thyroid nodules and differentiated thyroid cancer: the American Thyroid Association Guidelines Task Force on Thyroid Nodules and Differentiated Thyroid Cancer. Thyroid 2016;26:1-133.

9. Amin MB, Edge S, Greene F, Byrd DR, Brookland RK, Washington MK, et al. AJCC cancer staging manual. 8th ed. New York: Springer, 2017.

10. Kwak JY, Kim EK, Youk JH, Kim MJ, Son EJ, Choi SH, et al. Extrathyroid extension of well-differentiated papillary thyroid microcarcinoma on US. Thyroid 2008; 18:609-614.

11. Park JS, Son KR, Na DG, Kim E, Kim S. Performance of preoperative sonographic staging of papillary thyroid carcinoma based on the sixth edition of the AJCC/UICC TNM classification system. AJR Am J Roentgenol 2009;192:66-72.

12. Choi JS, Kim J, Kwak JY, Kim MJ, Chang HS, Kim EK. Preoperative staging of papillary thyroid carcinoma: comparison of ultrasound imaging and CT. AJR Am J Roentgenol 2009;193:871-878.

13. Moon HJ, Kim EK, Yoon JH, Kwak JY. Clinical implication of elastography as a prognostic factor of papillary thyroid microcarcinoma. Ann Surg Oncol 2012;19:2279-2287.

14. Park YJ, Kim JA, Son EJ, Youk JH, Park CS. Quantitative shear wave elastography as a prognostic implication of papillary thyroid carcinoma (PTC): elasticity index can predict extrathyroidal extension (ETE). Ann Surg Oncol 2013;20:2765-2771.

15. Jin ZQ, Lin MY, Hu WH, Li WY, Bai SJ. Gray-scale ultrasonography combined with elastography imaging for the evaluation of papillary thyroid microcarcinoma: as a prognostic clinicopathology factor. Ultrasound Med Biol 2014;40:1769-1777.

16. Gweon HM, Son EJ, Youk JH, Kim JA, Park CS. Preoperative assessment of extrathyroidal extension of papillary thyroid carcinoma: comparison of 2- and 3-dimensional sonography. J Ultrasound Med 2014;33:819-825.
17. Mete O, Rotstein L, Asa SL. Controversies in thyroid pathology: thyroid capsule invasion and extrathyroidal extension. Ann Surg Oncol 2010;17:386-391.

18. Jukkola A, Bloigu R, Ebeling T, Salmela P, Blanco G. Prognostic factors in differentiated thyroid carcinomas and their implications for current staging classifications. Endocr Relat Cancer 2004;11:571579.

19. Ito $Y$, Tomoda C, Uruno T, Takamura $Y$, Miya A, Kobayashi $K$, et al. Prognostic significance of extrathyroid extension of papillary thyroid carcinoma: massive but not minimal extension affects the relapsefree survival. World J Surg 2006;30:780-786.

20. Nixon IJ, Ganly I, Patel S, Palmer FL, Whitcher MM, Tuttle RM, et al. The impact of microscopic extrathyroid extension on outcome in patients with clinical T1 and T2 well-differentiated thyroid cancer. Surgery 2011;150:1242-1249.

21. Radowsky JS, Howard RS, Burch HB, Stojadinovic A. Impact of degree of extrathyroidal extension of disease on papillary thyroid cancer outcome. Thyroid 2014;24:241-244.

22. Andersen PE, Kinsella J, Loree TR, Shaha AR, Shah JP. Differentiated carcinoma of the thyroid with extrathyroidal extension. Am J Surg 1995; 170:467-470.

23. Bellantone $R$, Lombardi $C P$, Boscherini $M$, Ferrante $A$, Raffaelli $M$, Rubino $F$, et al. Prognostic factors in differentiated thyroid carcinoma: a multivariate analysis of 234 consecutive patients. J Surg Oncol 1998;68:237-241.

24. Rim JH, Chong S, Ryu HS, Chung BM, Ahn HS. Feasibility study of ultrasonographic criteria for microscopic and macroscopic extrathyroidal extension based on thyroid capsular continuity and tumor contour in patients with papillary thyroid carcinomas. Ultrasound Med Biol 2016;42:2391-2400.

25. Kebebew E, Greenspan FS, Clark OH, Woeber KA, McMillan A. Anaplastic thyroid carcinoma. Treatment outcome and prognostic factors. Cancer 2005;103:1330-1335.

26. Smallridge RC, Ain KB, Asa SL, Bible KC, Brierley JD, Burman KD, et al. American Thyroid Association guidelines for management of patients with anaplastic thyroid cancer. Thyroid 2012;22:11041139.

27. American Thyroid Association Surgery Working Group; American Association of Endocrine Surgeons; American Academy of Otolaryngology-Head and Neck Surgery; American Head and Neck Society, Carty SE, Cooper DS, et al. Consensus statement on the terminology and classification of central neck dissection for thyroid cancer. Thyroid 2009; 19:1153-1158.

28. Sohn YM, Kwak JY, Kim EK, Moon HJ, Kim SJ, Kim MJ. Diagnostic approach for evaluation of lymph node metastasis from thyroid cancer using ultrasound and fine-needle aspiration biopsy. AJR Am J Roentgenol 2010;194:38-43.

29. Na DG, Lim HK, Byun HS, Kim HD, Ko YH, Baek JH. Differential diagnosis of cervical lymphadenopathy: usefulness of color Doppler 
sonography. AJR Am J Roentgenol 1997;168:1311-1316.

30. Kim E, Park JS, Son KR, Kim JH, Jeon SJ, Na DG. Preoperative diagnosis of cervical metastatic lymph nodes in papillary thyroid carcinoma: comparison of ultrasound, computed tomography, and combined ultrasound with computed tomography. Thyroid 2008;18:411-418.

31. Shin JH, Baek JH, Chung J, Ha EJ, Kim JH, Lee YH, et al. Ultrasonography diagnosis and imaging-based management of thyroid nodules: revised Korean Society of Thyroid Radiology consensus statement and recommendations. Korean J Radiol 2016;17:370-395.

32. Cignarelli M, Ambrosi A, Marino A, Lamacchia O, Campo M, Picca $G$, et al. Diagnostic utility of thyroglobulin detection in fine-needle aspiration of cervical cystic metastatic lymph nodes from papillary thyroid cancer with negative cytology. Thyroid 2003;13:1163-1167.

33. Boi F, Baghino G, Atzeni F, Lai ML, Faa G, Mariotti S. The diagnostic value for differentiated thyroid carcinoma metastases of thyroglobulin $(\mathrm{Tg})$ measurement in washout fluid from fineneedle aspiration biopsy of neck lymph nodes is maintained in the presence of circulating anti-Tg antibodies. J Clin Endocrinol Metab 2006;91:1364-1369.

34. Roh JL, Park JY, Kim JM, Song CJ. Use of preoperative ultrasonography as guidance for neck dissection in patients with papillary thyroid carcinoma. J Surg Oncol 2009;99:28-31.

35. Loevner LA, Kaplan SL, Cunnane ME, Moonis G. Cross-sectional imaging of the thyroid gland. Neuroimaging Clin N Am 2008;18:445461.

36. Wang TS, Cheung K, Farrokhyar F, Roman SA, Sosa JA. A metaanalysis of the effect of prophylactic central compartment neck dissection on locoregional recurrence rates in patients with papillary thyroid cancer. Ann Surg Oncol 2013;20:3477-3483.

37. Gyorki DE, Untch B, Tuttle RM, Shaha AR. Prophylactic central neck dissection in differentiated thyroid cancer: an assessment of the evidence. Ann Surg Oncol 2013;20:2285-2289.

38. Randolph GW, Duh QY, Heller KS, LiVolsi VA, Mandel SJ, Steward $D L$, et al. The prognostic significance of nodal metastases from papillary thyroid carcinoma can be stratified based on the size and number of metastatic lymph nodes, as well as the presence of extranodal extension. Thyroid 2012;22:1144-1152.

39. Moreno MA, Edeiken-Monroe BS, Siegel ER, Sherman SI, Clayman GL. In papillary thyroid cancer, preoperative central neck ultrasound detects only macroscopic surgical disease, but negative findings predict excellent long-term regional control and survival. Thyroid 2012;22:347-355.

40. Choi YJ, Lee JH, Baek JH. Ultrasound elastography for evaluation of cervical lymph nodes. Ultrasonography 2015;34:157-164.

41. Lo WC, Cheng PW, Wang CT, Liao LJ. Real-time ultrasound elastography: an assessment of enlarged cervical lymph nodes. Eur
Radiol 2013;23:2351-2357.

42. Jung WS, Kim JA, Son EJ, Youk JH, Park CS. Shear wave elastography in evaluation of cervical lymph node metastasis of papillary thyroid carcinoma: elasticity index as a prognostic implication. Ann Surg Oncol 2015;22:111-116.

43. Lee HY, Lee JH, Shin JH, Kim SY, Shin HJ, Park JS, et al. Shear wave elastography using ultrasound: effects of anisotropy and stretch stress on a tissue phantom and in vivo reactive lymph nodes in the neck. Ultrasonography 2017;36:25-32.

44. Pedersen OM, Aardal NP, Larssen TB, Varhaug JE, Myking O, Vik-Mo $\mathrm{H}$. The value of ultrasonography in predicting autoimmune thyroid disease. Thyroid 2000;10:251-259.

45. Kim DW, Eun CK, In HS, Kim MH, Jung SJ, Bae SK. Sonographic differentiation of asymptomatic diffuse thyroid disease from normal thyroid: a prospective study. AJNR Am J Neuroradiol 2010;31:19561960.

46. Herh SJ, Kim EK, Sung JM, Yoon JH, Moon HJ, Kwak JY. Heterogeneous echogenicity of the thyroid parenchyma does not influence the detection of multi-focality in papillary thyroid carcinoma on preoperative ultrasound staging. Ultrasound Med Biol 2014;40:884-889.

47. Lee KJ, Cho YJ, Kim JG, Lee DH. How many contralateral papillary thyroid carcinomas can be missed? World J Surg 2013;37:780-785.

48. Moon HJ, Yoon JH, Kwak JY, Chung WY, Nam KH, Jeong JJ, et al. Positive predictive value and interobserver variability of preoperative staging sonography for thyroid carcinoma. AJR Am J Roentgenol 2011;197:W324-W330.

49. Paksoy N, Yazal K. Cervical lymphadenopathy associated with Hashimoto's thyroiditis: an analysis of 22 cases by fine needle aspiration cytology. Acta Cytol 2009;53:491-496.

50. Kim HJ, Kim NK, Choi JH, Sohn SY, Kim SW, Jin SM, et al. Associations between body mass index and clinico-pathological characteristics of papillary thyroid cancer. Clin Endocrinol (Oxf) 2013;78:134-140.

51. Tresallet $C$, Seman M, Tissier F, Buffet C, Lupinacci RM, Vuarnesson $H$, et al. The incidence of papillary thyroid carcinoma and outcomes in operative patients according to their body mass indices. Surgery 2014; 156:1145-1152.

52. Choi JS, Lee HS, Kim EK, Moon HJ, Kwak JY. The influence of body mass index on the diagnostic performance of pre-operative staging ultrasound in papillary thyroid carcinoma. Clin Endocrinol (Oxf) 2015;83:550-555.

53. Ganly I, Nixon IJ, Wang LY, Palmer FL, Migliacci JC, Aniss A, et al. Survival from differentiated thyroid cancer: what has age got to do with it? Thyroid 2015;25:1106-1114.

54. Nixon IJ, Kuk D, Wreesmann V, Morris L, Palmer FL, Ganly I, et al. Defining a valid age cutoff in staging of well-differentiated thyroid cancer. Ann Surg Oncol 2016;23:410-415. 